\title{
Retained textile foreign body: A rare cause of acute abdomen
}

\author{
José Caballero-Alvarado1,2, Carlos Ruiz-Urquiaga', Judith Sánchez-Zavaleta3, Edward Chávez-Cruzado² \\ 1. Hospital Regional Docente de Trujillo, Trujillo, Perú \\ 2. Escuela de Posgrado de la Universidad Privada Antenor Orrego, Trujillo, Perú \\ 3. Facultad de Medicina, Universidad Nacional de Trujillo, Trujillo, Perú
}

Correspondence: Dr José Caballero-Alvarado (jcaballeroa2@upao.edu.pe)

\begin{abstract}
(c) 2018 J. Caballero-Alvarado et al. This open access article is licensed under a (reative Commons Attribution 4.0 International License (http://creativecommons.org/licenses/by/4.0/), which permits unrestricted use, distribution, and reproduction in any medium, provided you give appropriate credit to the original author(s) and the source, provide a link to the Creative Commons license, and indicate if changes were made.
\end{abstract}

East Cent Afr J Surg. 2018 Apr;23(1):52-4 https://dx.doi.org/10.4314/ecajs.v23i1.10

\begin{abstract}
A retained textile foreign body in the abdominal cavity following surgery (gossypiboma, textiloma) is an iatrogenic complication that has medicolegal repercussions. This report presents a female patient who was seen in the emergency room with a history of hysterectomy, 8 years prior, due to severe haemorrhage associated with placenta accreta. She complained of moderate abdominal pain, which progressed over the previous 8 days. After physical examination and diagnostic imaging, an appendicular plastron complicated by abscess was diagnosed. During surgery, a mobile, omentum-wrapped mass was observed and excised. Extracorporeal inspection revealed the mass to be partially decomposed dressing gauze saturated with malodorous liquid. The patient recovered well and was discharged with no complications.
\end{abstract}

Keywords: retained textile foreign body, gossypiboma, acute abdomen

\section{Introduction}

Retained textile foreign bodies following surgery can occur in any location, with the abdominal cavity being the most frequent. The estimated incidence varies from 1 per 1000 procedures to 1 per 3000 procedures, ${ }^{1}$ although the actual number is unknown due to underreporting in the context of medicolegal and ethical repercussions. ${ }^{2}$ Retained foreign bodies go by a variety of names, including gossypiboma, textiloma, gauzoma, and cottonoid, all of which describe a cotton core mass surrounded by a foreign body reaction. ${ }^{3}$ Diagnosis is difficult because of the variable and nonspecific

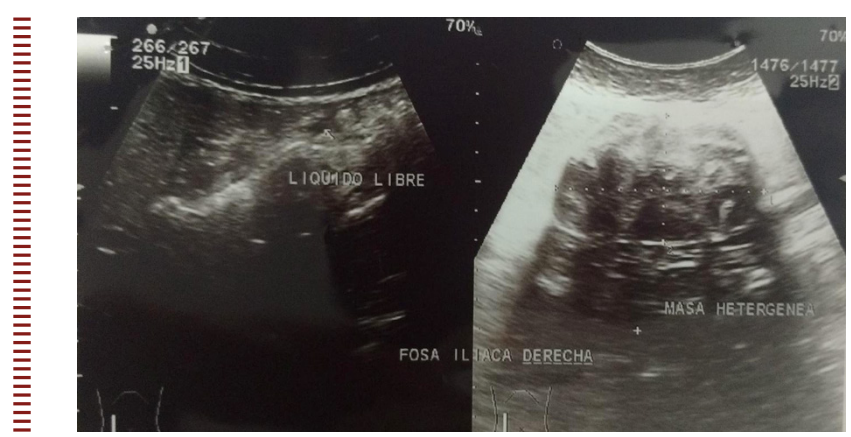

Figure 1. Abdominal ultrasound showing a heterogeneous mass in the right iliac fossa clinical picture; therefore, diagnostic imaging is usually necessary. Patient safety strategies, including the surgical safety checklist, are helpful in preventing such mishaps, but safety can only be optimized through the conscientious commitment of the surgical team.

\section{Case presentation}

A 40-year-old woman with a 10-year history of type 2 diabetes mellitus, which was well controlled with metformin, was admitted to the emergency room complaining of moderate to severe abdominal pain in the right flank and iliac fossa. She had undergone an emergency hysterectomy secondary to placenta accreta complicated by severe haemorrhage 8 years prior. The patient had also been suffering sporadic and self-limited episodes of mild to moderate abdominal pain for the previous 4 years, mainly over the right hemiabdomen. During this presentation, the physical examination showed a slightly distended, tender, and tympanic abdomen with a mobile palpable mass in the right iliac fossa. She had a heart rate of 102 beats/min, blood pressure of 100/70 $\mathrm{mmHg}$, respiratory rate of 20 breaths/min, and her oxygen saturation was $98 \%$, with an $\mathrm{FiO}_{2}$ of $21 \%$. An abdominal ultrasound scan revealed an appendicular plastron (Figure 1), and a 


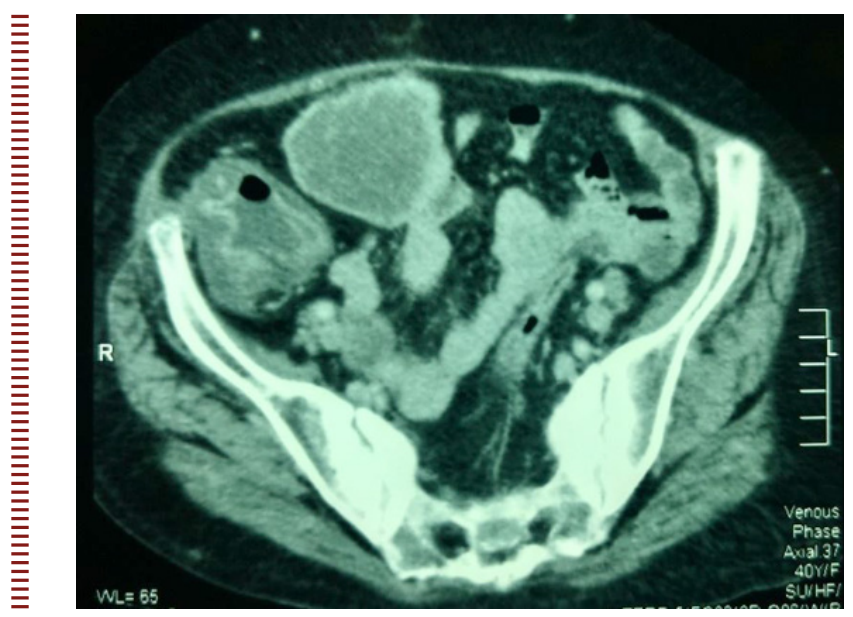

Figure 2. Abdominopelvic computed axial tomography image showing a plastron-like homogeneous mass in the right iliac fossa
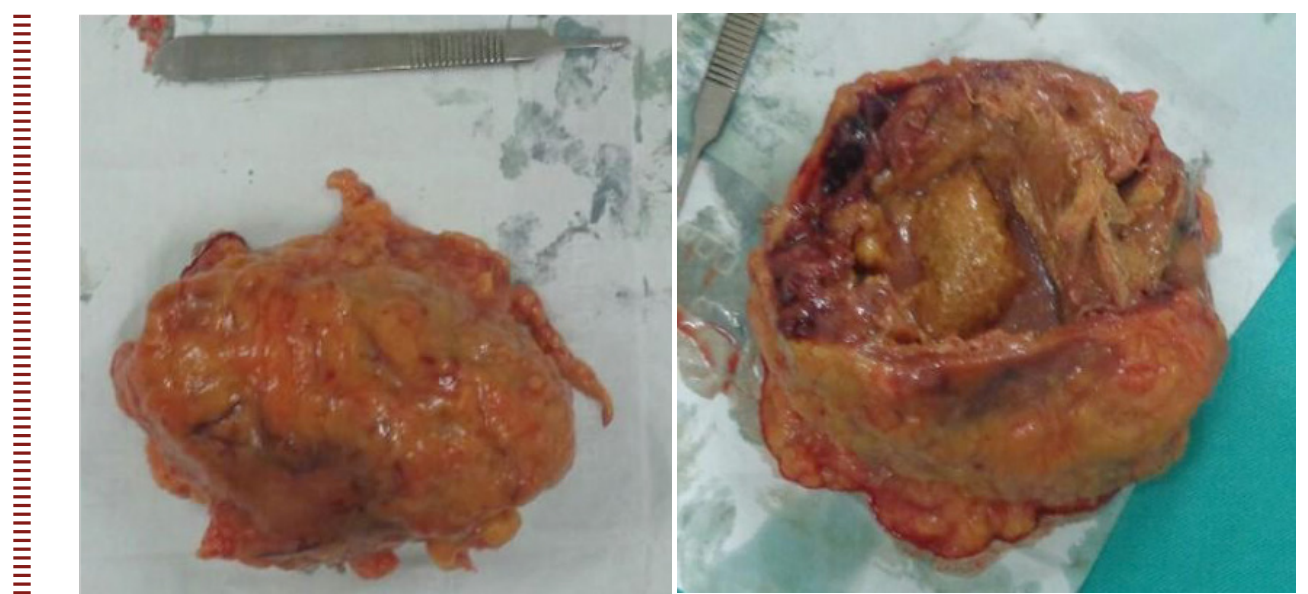

Figure 4. Excised, omentum-wrapped, $10 \mathrm{~cm} \times 8 \mathrm{~cm}$ tumour outside the abdominal cavity, with (right) dressing gauze and a malodorous fluid visualized in the open tumour

contrasted-enhanced computed tomography (CT) scan of the abdominopelvic area revealed an irregular appearance of the ascending colon and the right transverse colon walls, with mural oedema and a homogeneous collection of thickened wall in the right iliac fossa (Figure 2).

Laboratory results were as follows: thrombocytosis $(631,000 / \mu \mathrm{L})$, leukocytosis $(6130$ leukocytes/ $\mu \mathrm{L})$ with a normal leukocyte differential, haematocrit of $35.9 \%$, creatinine of $0.5 \mathrm{mg} / \mathrm{dL}$, glucose of $127 \mathrm{mg} / \mathrm{dL}$, aspartate transaminase (AST) of $109 \mathrm{U} / \mathrm{L}$, and alanine transaminase of $64 \mathrm{U} / \mathrm{L}$.

A median infraumbilical laparotomy revealed a mobile, omentum-wrapped mass, $10 \mathrm{~cm} \times 8 \mathrm{~cm}$, in the right iliac fossa, which was excised by partial omentectomy (Figure 3 ). Upon extracorporeal examination, the mass was observed to be partially decomposed dressing gauze saturated with a malodorous liquid (Figure 4). The patient remained hospitalized for 2 days, and she was discharged with no complications. female sex. ${ }^{5}$ diagnosis difficult.

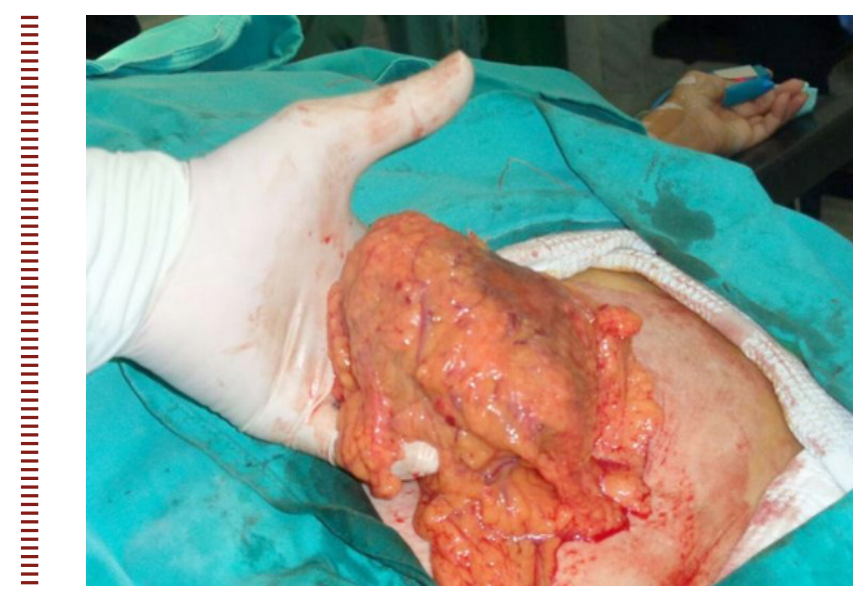

Figure 3. Mobile, omentum-wrapped, $10 \mathrm{~cm} \times 8 \mathrm{~cm}$, intra-abdominal tumour in the right iliac fossa

\section{Discussion}

Retained nonabsorbable surgical material, made of a cotton matrix, can cause mild to severe surgical complications, depending on its location and the time of evolution. ${ }^{4}$ The medicolegal implications of such cases favour underreporting; therefore, the actual incidence is unknown.

Several factors have been associated with gossypibomas, such as operations performed as emergencies; inaccurate recording of swab counts; unexpected intraoperative events, findings, or adjustments; and patient factors, such high body mass index (BMI) and

The clinical picture may include abdominal pain, abdominal mass, rectal bleeding, intestinal obstruction, fever, diarrhoea and weight loss ${ }^{6}$; the time of presentation and duration can vary from 3 days to 40 years, ${ }^{7}$ which makes early

The time of presentation depends on the type of tissue reaction generated, either an aseptic fibrinous or an exudative response. ${ }^{8}$ Aseptic fibrinous inflammatory reactions cause adhesions around the foreign body or encapsulation of it with omentum and nearby organs. This may not give manifestations in a variable time, or cause insidious evolution; therefore, incidental diagnosis is frequent. On the other hand, the exudative inflammatory reaction, with abscess formation, can occur with a systemic inflammatory response if there is an external opening (similar to an acute abdomen), or with an erosion caused by the foreign body in a hollow organ (intestine) that can lead to the spontaneous expulsion of it, through the mouth or rectum without any eventuality. This type of reaction usually becomes symptomatic in the early postoperative period. ${ }^{9-11}$ 
The presented patient was asymptomatic for 4 years, after that, she had sporadic abdominal pain, which intensified few days before her admission to the emergency department; there are few cases described in the literature with a time of presentation of these characteristics. Susmallian et al. ${ }^{7}$ describe a case of a woman, 9 years after a cesarean section, who presents abdominal pain and fever; the laparotomy finding was a retained surgical dressing.

All members of the team involved in a surgical intervention should be alert and vigilantly adhere to all implemented strategies to guarantee the patient's safety. For this reason, the World Health Organization launched the "Safe Surgery Saves Lives" initiative and continues to promote the Surgical Safety Checklist. One of the checklist components is the completion of instrument, sponge, and needle counts before the patient leaves the operating room. ${ }^{13}$ This tool has proven to be effective in contexts of adequate application, which implies conceptual and procedural adherence by all health personnel involved in emergency and elective surgeries, thus contributing to the reduction of incidents that threaten patient safety. ${ }^{14}$

\section{Conclusions}

We described the case of a woman who presented to the emergency room with an acute abdomen. She underwent surgery with the preoperative diagnosis of appendicular plastron with abscess. The surgical procedure allowed the identification of a retained foreign body in the abdominal cavity. Such incidents are preventable through properly implemented patient safety strategies.

\section{Competing interests}

All authors declare that they have no competing interests related to this work.

\section{References}

1. Bani-Hani KE, Gharaibeh KA, Yaghan RJ. Retained surgical sponges (gossypiboma) Asian J Surg. 2005 Apr;28(2):109-15. doi: 10.1016/S1726-4901(08)70051-0.

2. Kaplan M, lyiköşker HI. A new complication of retained surgical gauze: development of malignant fibrous histiocytoma-report of a case with a literature review. World J Surg Oncol. 2012 Jul 9;10:139. doi: 10.1186/1477-7819-10-139.

3. Silva SM, Sousa JB. [Gossypiboma after abdominal surgery is a challenging clinical problem and a serious medicolegal issue]. [Article in Portuguese]. Arq Bras Cir Dig. 2013 Jun;26(2):140-3. doi: 10.1590/ S0102-67202013000200015.

4. Arikan S, Kocakusak A. Retained textile foreign bodies: experience of 27 years. Acta Med Port. 2015 JulAug;28(4):494-500. Epub 2015 Aug 31.

5. Hariharan D, Lobo DN. Retained surgical sponges, needles and instruments. Ann R Coll Surg Engl. 2013 Mar;95(2):87-92. doi: 10.1308/003588413X13511609957218.
6. Grant-Orser A, Davies P, Singh SS. The lost sponge: patient safety in the operating room. CMAJ. 2012 Aug 7;184(11):1275-8. doi: 10.1503/cmaj.110900. Epub 2012 Jul 3.

7. Susmallian S, Raskin B, Barnea R. Surgical sponge forgotten for nine years in the abdomen: A case report. Int J Surg Case Rep. 2016;28:296-299. doi: 10.1016/j. ijscr.2016.10.026. Epub 2016 Oct 14

8. Yildirim S, Tarim A, Nursal TZ, Yildirim T, Caliskan K, Torer N, et al. Retained surgical sponge (gossypiboma) after intraabdominal or retroperitoneal surgery: 14 cases treated at a single center. Langenbecks Arch Surg. 2006 Aug;391(4):390-5. doi: 10.1007/s00423005-0581-4. Epub 2005 Sep 17.

9. Cheng TC Chou AS, Jeng CM, Chang PY, Lee CC. Computed tomography findings of gossypiboma. J Chin Med Assoc. 2007 Dec;70(12):565-9. doi: 10.1016/S17264901(08)70063-7.

10. Kansakar R, Thapa P, Adhikari S Intraluminal migration of gossypiboma without intestinal obstruction for fourteen years. JNMA J Nepal Med Assoc. 2008 Jul-Sep:47(171):136-8
11. Düx M, Ganten M, Lubienski A, Grenacher L. Retained surgical sponge with migration into the duodenum and persistent duodenal fistula. Eur Radiol. 2002 Dec;12 Suppl 3:S74-7. doi: 10.1007/s00330-0021408-0. Epub 2002 May 7.

12. Velasco-Mata S, Díaz-Gómez M, CovaBianco T, Hopp-Mora E, Rodriguez-Rojas $R$, Chirinos-Malave $Y$, et al. Duodenal gossypiboma: a case report and literature review. Invest Clin. 2015 Sep;56(3):296300.

13. World Health Organization (WHO). Safe surgery [Internet]. Geneva: WHO; c2014 [cited 2016 Nov 1]. Available from: http:// www.who.int/patientsafety/safesurgery/en/.

14. Anwer M, Manzoor S, Muneer N, Qureshi S. Compliance and effectiveness of WHO surgical safety check list: a JPMC audit. Pak J Med Sci. 2016 Jul-Aug;32(4):831-5. doi: $10.12669 /$ pjms.324.9884. 